\title{
Perivascular spread of adenoid cystic carcinoma: a novel imaging sign
}

\author{
Sandeep Kumar, ${ }^{1}$ Roumina Hasan, ${ }^{2}$ Santhana Kumar Paulraj, ${ }^{3}$ Mary Mathew ${ }^{4}$
}

${ }^{1}$ Department of

Radiodiagnosis, Kasturba Medical College, Manipal, Manipal, Karnataka, India 2Department of Pathology, Melaka Manipal Medical College (Manipal Campus) Manipal, Karnataka, India ${ }^{3}$ Department of

Radiodiagnosis, Manipal University, Manipal, Karnataka, India

${ }^{4}$ Department of Pathology, Kasturba Medical College, Manipal, Karnataka, India

Correspondence to Dr Roumina Hasan, drrouminahasan@gmail.com

Accepted 9 July 2015

CrossMark

To cite: Kumar $S$, Hasan $R$, Paulraj SK, et al. BMJ Case Rep Published online: [please include Day Month Year] doi:10.1136/bcr-2015210969

\section{DESCRIPTION}

A 75-year-old woman presented with a mildly painful mass over her right lower jaw for 3 years. The mass presented as a small nodule and progressively increased to the present size. Additional symptoms included dull aching pain in the right lower jaw for the last 15 years, radiating to the right ear and not related to chewing or salivation, with temporary relief on medications. She reported pain on opening her mouth and had difficulty swallowing. On examination, an oval shaped $3 \times 2 \mathrm{~cm}$ tender mass was found overlying the angle of the right mandible. The mass was hard in consistency, with ill-defined margins, and was fixed to the underlying muscle. A few small papillomatous nodules were seen in the overlying skin. There was also fullness in the right floor of the mouth near the region of the opening of submandibular papilla. However, no calculus was palpated on bidigital examination.

Ultrasound of the neck revealed a relatively well-defined hypoechoic mass, measuring $2.5 \times 2 \times 1.4 \mathrm{~cm}$, overlying the right angle of the mandible, showing anteromedial extension as a cuff of soft tissue centred on a vessel, extending along the medial margin of the body of the mandible, superficial to the mylohyoid muscle (figure $1 \mathrm{~A}-\mathrm{C}$ ). CT scan showed heterogeneous enhancement of the mass lesion located at the angle of the mandible with extension along the submental branch of the

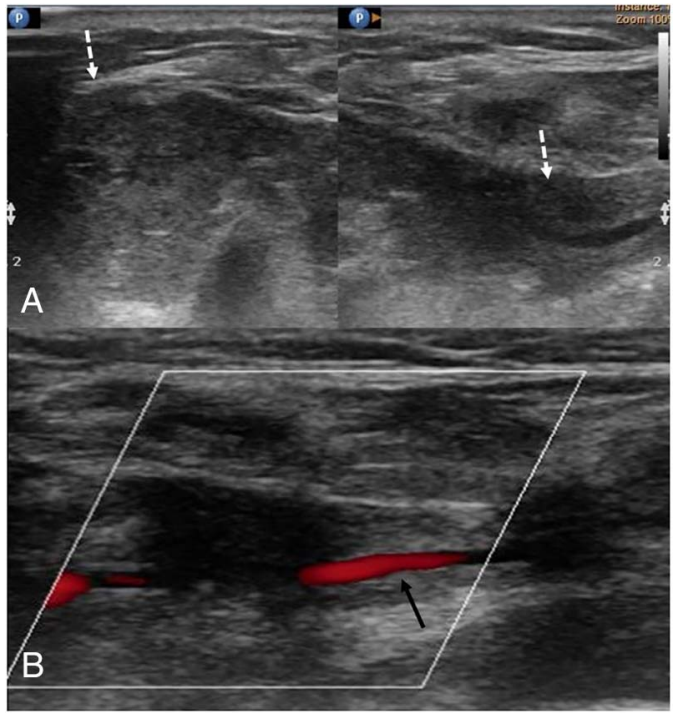

Figure 1 (A) Longitudinal ultrasound using the split-screen function showing a well-defined hypoechoic mass lesion (dashed arrow) showing linear extension as a cuff of tissue centred on a vessel. (B) Colour Doppler image revealing the patent lumen of the vessel encased by the mass lesion (white arrow). facial artery, coursing anterolateral to the right submandibular gland, between the medial margin of the mandible and mylohyoid muscle. There were multiple small enhancing subcutaneous nodules seen in the overlying skin (figure $2 \mathrm{~A}-\mathrm{D}$ ).

Fine-needle aspiration cytology of the mass revealed features suggestive of adenoid cystic carcinoma (ACC). A complete surgical excision of the mass along with right submandibular gland and supraomohyoid neck dissection was performed. Histopathology findings were consistent with minor salivary gland ACC with perineural and perivascular invasion (figure 3A, B). The skin nodule and its underlying subcutaneous tissue were infiltrated by the tumour. The excised submandibular gland and cervical lymph nodes were free from tumour. CT of the thorax was normal. The patient was diagnosed as minor salivary gland ACC, grade II, mixed pattern, TNM stage T4N0M0 and received postsurgical adjuvant radiotherapy. On 6 months follow-up, the patient remains symptom free.

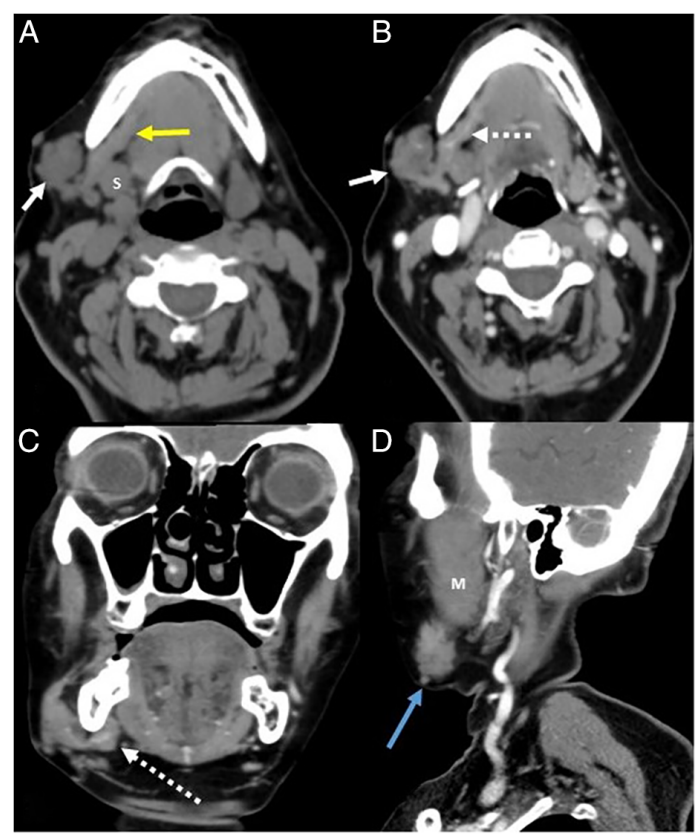

Figure 2 CT of the neck. Axial view (A) plain and (B) contrast images revealing a heterogeneously enhancing mass lesion (white arrow) at the angle of the right mandible, showing anteromedial soft tissue extension (yellow arrow) along the enhancing submental branch of the facial artery (dashed arrow). (C) Coronal image revealing the extension of the mass lesion with its central vessel (dashed arrow) in the submandibular space between the medial margin of the mandible and mylohyoid muscle. (D) Sagittal view demonstrating the relationship of the mass to the masseter muscle and subcutaneous nodules in overlying skin (blue arrow; $\mathrm{S}$, submandibular gland; $\mathrm{M}$, masseter muscle). 
Figure 3 (A) Photomicrograph showing adenoid cystic carcinoma with cribriform and tubular pattern along with perivascular spread (black arrow; H\&E $\times 20$ ). (B) High power view showing perivascular spread of tumour cells along the artery (H\&E $\times 200)$.

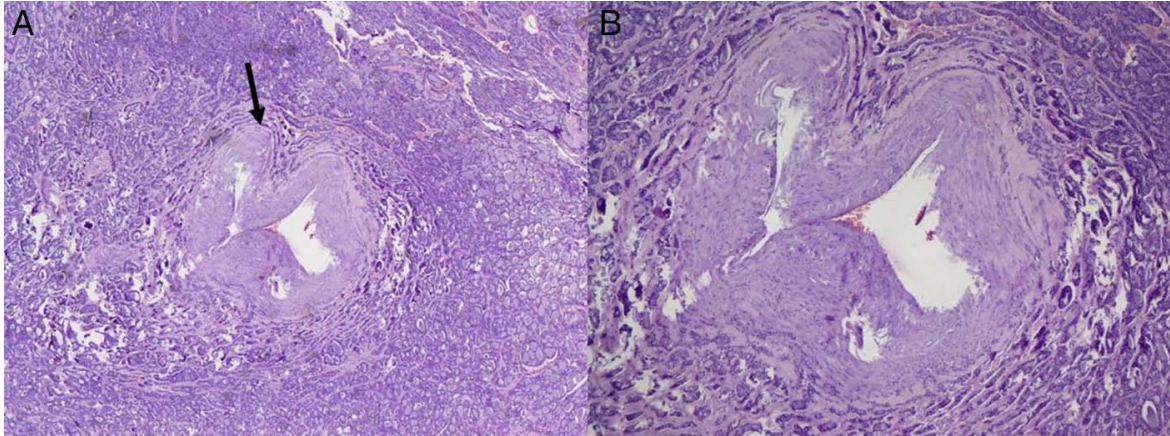

ACC is a rare, slow-growing secretory gland neoplasm, accounting for $1 \%$ of all malignant tumours of the oral and maxillofacial region, and $10 \%$ of all salivary gland neoplasms, including both major and minor salivary glands. ${ }^{1}$ The incidence of ACC is more frequent in minor salivary glands as compared with major salivary glands and the reported sites include the nose, paranasal sinuses, palate, trachea, tongue, lacrimal glands, larynx, breast, prostate, uterus, vulva, skin and the external auditory canal. ${ }^{12}$ Histopathologically, ACCs show three growth patterns, namely cribriform, tubular and solid form, and they are graded according to Batsakis et al into three grades. Grade I includes tubular and cribriform pattern, no solid areas, cytologically bland cells and little or no mitoses. Grade II shows either pure cribriform or mixed pattern with less than $30 \%$ solid areas and cytologically intermediate cells. Grade III shows more than $30 \%$ solid areas, usually with necrosis, more cellular atypia and mitoses. ${ }^{3}$

ACCs have a propensity for perineural and perivascular invasion, which is reflected in their high local recurrence rates and late-onset distant metastatic presentations. Perineural spread (PNS) of disease, which documents the presence of gross tumour spread along a nerve, in continuation with but at least partly distinct from the main tumour mass, has been reported in $20-80 \%$ of ACCs. ${ }^{4}$ The incidence of perivascular invasion has been reported to be $15 \%$ in ACC and has been found to be associated with a high rate of pulmonary metastasis. ${ }^{5}$ However, unique to our case the perivascular spread of ACC along an artery has not yet been documented in the literature.

The underlying mechanism of PNS is controversial and the various theories proposed are: (1) the tumour propagates along the lymphatics of nerve, (2) nerves provide the path of least resistance and (3) neural cell adhesion molecules (NCAM) have a role to play. ${ }^{5}$ NCAM is a membrane-bound glycoprotein belonging to the immunoglobulin supergene family, described to mediate homophilic binding between neighbouring cells, and heterophilic interactions between cells and extracellular matrix components. It plays an important role in cellular proliferation, adhesion and migration, factors which may account for its role in perineural invasion in various neoplasms. ${ }^{6}$ Recently, overexpression of nerve growth factor and vascular endothelial growth factor (VEGF) has been reported in tumours showing perineural and perivascular invasion, but the exact mechanism for preferred tumour extension along the nerves and vessels is still unclear. ${ }^{7}$ It is plausible that the VEGF secreted by the tumour cells is attracted to and attaches to the VEGF receptors in the blood vessel wall and this facilitates the perivascular tumour growth.

Owing to its excellent soft tissue contrast resolution, MRI is the standard for diagnosing PNS of ACC. It is imperative that a patient with PNS of ACC should be investigated with MRI for concomitant or exclusive PNS, especially since the course of the artery and nerve are close together, and distinction from classical PNS can be challenging.

To conclude, we would like to highlight this unique feature of perivascular spread of ACC in a minor salivary gland tumour as a clue to aid clinicians and radiologists to accurately diagnose and stage the tumour, and plan the appropriate surgical strategy.

\section{Learning points}

- Adenoid cystic carcinoma (ACC) is a rare, malignant tumour of secretory glands, having a propensity for perineural and perivascular invasion.

- Perineural extension of the tumour is a well-recognised feature of ACC and is associated with increased locoregional recurrence.

- We document a unique presentation of ACC, occurring as a cuff of tumour mass extending along a vessel.

- A high index of suspicion is warranted for the possibility of adenoid cystic carcinoma in the setting of a mass showing extension along a blood vessel, and this clue could provide accurate preoperative surgical mapping, staging and prognosis.

Acknowledgements The authors would like to express our gratitude to $\mathrm{Dr}$ Rajagopal Kadavigere for his constant support in preparation of this manuscript.

Contributors SK diagnosed the condition and conceptualised the idea of the manuscript, and all the authors contributed to design, literature search and final editing of the manuscript.

Competing interests None declared.

Patient consent Obtained.

Provenance and peer review Not commissioned; externally peer reviewed.

\section{REFERENCES}

1 Chummun S, McLean NR, Kelly CG, et al. Adenoid cystic carcinoma of the head and neck. Br J Plast Surg 2001;54:476-80.

2 Hellquist $\mathrm{H}$, Skalova A. Adenoid cystic carcinoma. Histopathology of the salivary glands. Heidelberg: Springer Berlin, 2014:221-60. [cited 26 Apr 2015]. http://link. springer.com/chapter/10.1007/978-3-540-46915-5_8

3 Batsakis JG, Luna MA, el-Naggar A. Histopathologic grading of salivary gland neoplasms: III. Adenoid cystic carcinomas. Ann Otol Rhinol Laryngol 1990;99:1007-9.

4 Shimamoto $H_{1}$ Chindasombatjaroen J, Kakimoto N, et al. Perineural spread of adenoid cystic carcinoma in the oral and maxillofacial regions: evaluation with contrast-enhanced CT and MRI. Dentomaxillofac Radiol 2012;41:143-51.

$5 \mathrm{Ko}$ YH, Lee MA, Hong YS, et al. Prognostic factors affecting the clinical outcome of adenoid cystic carcinoma of the head and neck. Jpn J Clin Oncol 2007;37:805-11.

6 Hutcheson JA, Vural E, Korourian $S$, et al. Neural cell adhesion molecule expression in adenoid cystic carcinoma of the head and neck. Laryngoscope 2000;110:946-8

7 Hao L, Xiao-lin N, Qi C, et al. Nerve growth factor and vascular endothelial growth factor: retrospective analysis of 63 patients with salivary adenoid cystic carcinoma. Int J Oral Sci 2010;2:35-44. 
Copyright 2015 BMJ Publishing Group. All rights reserved. For permission to reuse any of this content visit http://group.bmj.com/group/rights-licensing/permissions.

BMJ Case Report Fellows may re-use this article for personal use and teaching without any further permission.

Become a Fellow of BMJ Case Reports today and you can:

- Submit as many cases as you like

- Enjoy fast sympathetic peer review and rapid publication of accepted articles

- Access all the published articles

- Re-use any of the published material for personal use and teaching without further permission

For information on Institutional Fellowships contact consortiasales@bmjgroup.com

Visit casereports.bmj.com for more articles like this and to become a Fellow 